\title{
Evaluation of Apical Transportation And Centering Ability of Three Different NITI Endodontic Files- A Comparative In Vitro CBCT Study
}

\author{
Dr. Tirthankar Bhaumik, BDS (UNB, W.B.) ${ }^{1}$, Dr. Monojit Roy, BDS (C.U) ${ }^{2}$, \\ Dr. Utpal Kumar Das, BDS (C.U.), MDS (BHU) ${ }^{3}$, Dr. Kaushik Dutta, \\ BDS (WBUHS) MDS (MJPRU) ${ }^{4}$ \\ ${ }^{1,2}$ Post Graduate Students, Department Of Conservative Dentistry \&Endodontics, Guru Nanak Institute Of \\ Dental Sciences And Research, Panihati, Kolkata-114, West Bengal, India \\ ${ }^{3}$ Professor And Head Of The Department, Department Of Conservative Dentistry \& Endodontics, Guru Nanak \\ Institute Of Dental Sciences And Research Panihati, Kolkata-114, West Bengal, India \\ ${ }^{4}$ Senior Lecturer Department of Oral and Maxillofacial Radiology, Guru Nanak Institute Of Dental Sciences \\ and Research ,Panihati, Kolkata-114, West Bengal, India
}

\begin{abstract}
:
Background: Endodontic instruments, while performing, is expected to remain centered in root canal to prevent apical transportation. Hence assessment of centering ability of newer rotary NiTi file systems becomes essential for effective cleaning \& shaping.

Aims and objectives: Comparative CBCT evaluation of apical transportation and centering ability of Protaper Next, Hyflex CM and Twisted file.

Material and Method: Total of 24 extracted maxillary first molars were collected, randomly and equally divided into three following groups- $\mathrm{Gr} A, G r B, G r C(n=8)$. Every tooth was embedded into the wax block maintaining the groups and pre instrumentation $C B C T$ was done. After that the MB canals were instrumented by Protaper-Next in Gr A, Hyflex CM in Gr B and Twisted file In Gr C respectively and irrigated by $2.5 \% \mathrm{NaOCl}$ and $17 \%$ EDTA during and after preparation. Then teeth were subsequently re-embedded into the wax block maintaining the groups and post instrumentation CBCT was done. The pre and the post procedural scan images were analyzed and compared for the changes.

Result: Mesio-distally TF files showed least apical transportation with highest centering ability and buccolingually HCM showed the same observation. In both directions PTN showed apical highest transportation and lowest centering ability.

Conclusion: Canal transportation and centering ability of instruments in curved canals when compared then it was revealed that mesio-distally Twisted files and bucco-lingually Hyflex CM file exhibited better centering and minimum or nil transportation.
\end{abstract}

Keywords - Comparative, Centering ability, Evaluation, In-Vitro, Transportation

\section{Introduction}

The main goal of root canal preparation is to clean the root canal system while maintaining the original shape of the canal(s). ${ }^{1}$ According to Walton et al $(1928)^{2}$ the canals prepared with stainless steel instruments only cleaned superficially and the pulp tissue was not removed completely. Stainless steel files create aberrations, probably as a result of the inherent stiffness of stainless steel, which is compounded by instrument design and canal shape. ${ }^{3}$ The introduction of nickel-titanium (NiTi) rotary files to endodontics almost two decades ago has changed the concept and way root canal preparations are performed, enabling more complicated root canal systems to be shaped with fewer procedural errors. ${ }^{4}$ Development of nickel-titanium (NiTi) rotary instruments has provided easier and faster canal instrumentation and has minimized the procedural errors such as ledge, zip, canal transportation and stripping. ${ }^{5}$ Recently, thermal treatment of NiTi alloy has been used to optimize the mechanical properties of NiTi alloy. ${ }^{6-11}$

The newer Protaper next (Dentsply Tulsa Dental Specialties) file system is designed with rectangular cross section design for greater strength. The patented design's axis of rotation differs from the center of mass. As a result, only two points of the rectangular cross section touch the canal wall at a time. It is used with unique asymmetric rotary motion that further enhances Protaper canal shaping efficiency. These files are manufactured with M-Wire NiTi alloy for increased flexibility and resistance to cyclic fatigue. ${ }^{4}$

Hyflex CM rotary instruments (Coltene-Whaledent, Allstetten, Switzerland) are made from a new type of NiTi wire, namely CM wire(controlled memory), that has been subjected to proprietary thermomechanical 
processing. ${ }^{12}$ It has been manufactured by a unique process that controls the material's memory, making the files extremely flexible but without the loss of shape memory typical of other NiTi files. ${ }^{13}$

Twisted file (TF) (SybronEndo, Orange, CA, USA) is another new rotary file system with a triangular cross section. Production of Twisted file implements a specific R-phase heat treatment which allows twisting of the NiTi wire. This proprietary technology is used to optimize the molecular phase and properties of NiTi. Therefore, the resulting crystalline structure modification, which has been shown to be better than traditionally processed materials, maximizes the file flexibility and resistance to fracture. ${ }^{14}$

But all instruments and instrumentation techniques have a tendency to transport and alter the original canal shape, especially when the curvature is prominent and being negotiated for the first time. ${ }^{15}$ Thus the aim of this in-vitro study was to compare the apical transportation and centering ability of three recently introduced NiTi file systems- 1) Protaper Next, 2) Hyflex CM, 3) Twisted file using 'Cone beam computed tomography.'

\section{Materials and Methods}

Total of 24 extracted maxillary first molars with mesiobuccal root curvatures ranging between 15-30 degrees (according to Schneider's method) having no cracks or anomalies were collected and stored in formalin.[Figure 1] Access cavity was prepared using a high-speed round carbide bur (Dentsply, Maillefer) with water spray.A size $10 \mathrm{~K}$-file (Dentsply, Maillefer) was placed into the mesiobuccal canal(MB1) until it was visible at the apical foramen and the working length established $0.5 \mathrm{~mm}$ short of this length. If the apical foramen permits an easy pass of 10k file which means apical diameter larger than tip diameter of $10 \mathrm{k}$ file and then tooth was kept outside from the study. The teeth were randomly divided into the three following groups- $\mathrm{Gr}$ A, Gr B, Gr C (n=8). Teeth were embedded into the wax block maintaining the groups and initial CBCT of all sample were made.

After pre instrumentation CBCT, all mesio-buccal root canal was instrumented as below.

Gr.A was prepared by Protaper-Next file system(X2, 6\% 25)

Gr. B was prepared by Hyflex CM $(6 \% 25)$

Gr. C was prepared by Twisted file (6\% 25)

All instrumented canals were irrigated by $2.5 \% \mathrm{NaOCl}$ and $17 \%$ EDTA during and after preparation. Then teeth were re-embedded into the wax block maintaining the groups and post instrumentation CBCT was done. [Figure 2] Both pre and post instrumented CBCT was seen by iRYS viewer version 5.6[Installation package: 5.6.0].

\section{Evaluation:[Figure 3 \& 4]}

The shaping ability of the instruments were assessed from pre and post instrumented CBCT, for crosssectional (apical transportation and centering ability) changes at the level $0.5 \mathrm{~mm}$ from the apex by NNT viewer softwer.

Evaluation of canal transportation - To compare the degree of canal transportation, a technique developed by Bergmanset $\mathrm{al}^{16}$ was used. Transportation in all samples in all the groups was calculated using the following formula:

$\{(\mathrm{A} 1-\mathrm{A} 2)-(\mathrm{B} 1-\mathrm{B} 2)\}$ Mesio distal

$\{(\mathrm{X} 1-\mathrm{X} 2)-(\mathrm{Y} 1-\mathrm{Y} 2)\}$ Bucco-lingual

According to this formula, a result of ' 0 ' indicates no canal transportation. Results other than ' 0 ' means transportation has occurred.

Evaluation of centering ability - According to Gambillet al. "17"the mean centering ratio" indicates the ability of the instrument to stay centered in the canal. This ratio was calculated in all samples in all the groups using the following ratio:

$(\mathrm{A} 1-\mathrm{A} 2) /(\mathrm{B} 1-\mathrm{B} 2)$ and $(\mathrm{X} 1-\mathrm{X} 2) /(\mathrm{Y} 1-\mathrm{Y} 2)$

If these numbers are not equal, the lower figure is considered the numerator of the ratio. According to this formula, a result of ' 1 ' indicates perfect centering.

\section{Statistical Analysis}

Statistical Analysis was performed with help of Epi Info (TM) 3.5.3. EPI INFO is a trademark of the Centers for Disease Control and Prevention (CDC).

Descriptive statistical analysis was performed to calculate the means with corresponding standard error (s.e.). Also One Way Analysis of variance (ANOVA) followed by post hocTukey's Test was performed with the help of Critical Difference (CD) or Least Significant Difference (LSD) at 5\% and 1\% level of significance to compare the mean values. $\mathrm{p}<0.05$ was taken to be statistically significant.

Table 1 showing the statistical analysis of apical canal transportation in three groups under study where one way (ANOVA) showed that for MD direction there was significant difference in epical transportation of the three groups. As per CD mean epical transportation of PTN was significantly highest of all followed by HCM and for BL direction there was significant difference in epical transportation of the three groups. As per CD 
mean epical transportation of PTN was significantly highest of all followed by TF. These findings are graphically represented in graph 1 and 2 respectively.

Table 2 showing the statistical analysis of centering ability in three groups under study where one way (ANOVA) showed that for MD direction there was significant difference in centering ability of the three groups. As per CD mean centering ability of PTN was lowest with significantly highest ratio value among all followed by HCM and for BL direction there was significant difference in centering ability of the three groups. As per CD mean centering ability of PTN was lowest with significantly highest ratio value among all followed by TF. These findings are also graphically represented in graph 3 and 4 respectively.

\section{Discussion}

The goal of instrumentation is to produce a continuously tapered preparation that maintains the canal anatomy, keeping the foramen as small as possible. 18,19

But sometimes deviation from the original canal curvature may happen during root canal preparation and it can lead to:

1). Excessive and inappropriate dentin removal. ${ }^{20}$

2). Straightening of the canal and creation of a ledge in the dentinal wall. ${ }^{21}$

3). A biochemical defect known as an elbow which forms the coronal to the elliptical-shaped apical seal. ${ }^{22}$

4). Canals with hourglass appearance in cross-section that requires stripping. ${ }^{20}$

5). Over preparation that weakens the tooth, resulting in fracture of the root. ${ }^{20}$

There are various parameters that affect canal-centering abilities are: ${ }^{23}$

1) Alloys used in manufacturing instruments

2) Instrument design

i. Cross-section

ii. Taper,

iii. Tip.

According to Kandaswamy et al, 2009, ${ }^{23} \mathrm{Ni}-\mathrm{Ti}$ instruments show better canal-centering ability than stainless steel instruments and instruments with noncutting tips, less cross-sectional area \& taper will show better canal-centering ability.In other hand transportation is defined as the undesired deviation of canal's original shape to a new iatrogenic location of the external exit of the canal. 1Eventually, apical transportation may lead to zipping or perforation of the canal. ${ }^{24}$ Apical transportations that are more than $0.3 \mathrm{~mm}$ can jeopardize the outcome of treatment due to the significant decrease in the sealing ability of root filling material. ${ }^{25}$

Among different methods for the evaluation of apical transportation and shaping ability of various instruments and preparation techniques, CBCT imaging is one of the latest innovations that provide detailed three-dimensional observations at a low radiation dose with higher resolutions leads to increased accuracy and diagnostic capability ${ }^{1}$

In this present study we evaluated preparation quality in terms of apical transportation and centering ability of Protaper Next, Hyflex CM and Twisted file system with the help of CBCT in mesiobuccal roots of extracted maxillary first molars with curvature of $15^{\circ}$ to $30^{\circ}$. The preoperative and postoperative images of the cross-section of apical foramen, facilitates the evaluation. Result of this present study showed that highest mean apical transportation and lowest mean centering ability was produced by Protaper Next file system in both mesio-distal(MD) and bucco-lingual(BL) direction. Mesio-distally TF and bucco-lingually HCM showed least apical transportation with highest centering ability and in both cases result of the study was statistically significant $(\mathrm{P}<0.05)$.

\section{Graphs}

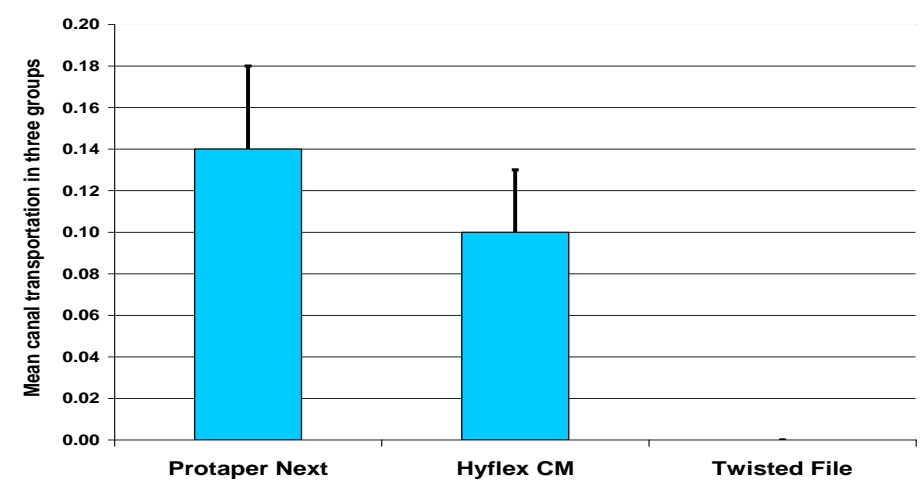

Graph 1: Representation of mean transportation at apical levels in three groups(MD direction) 


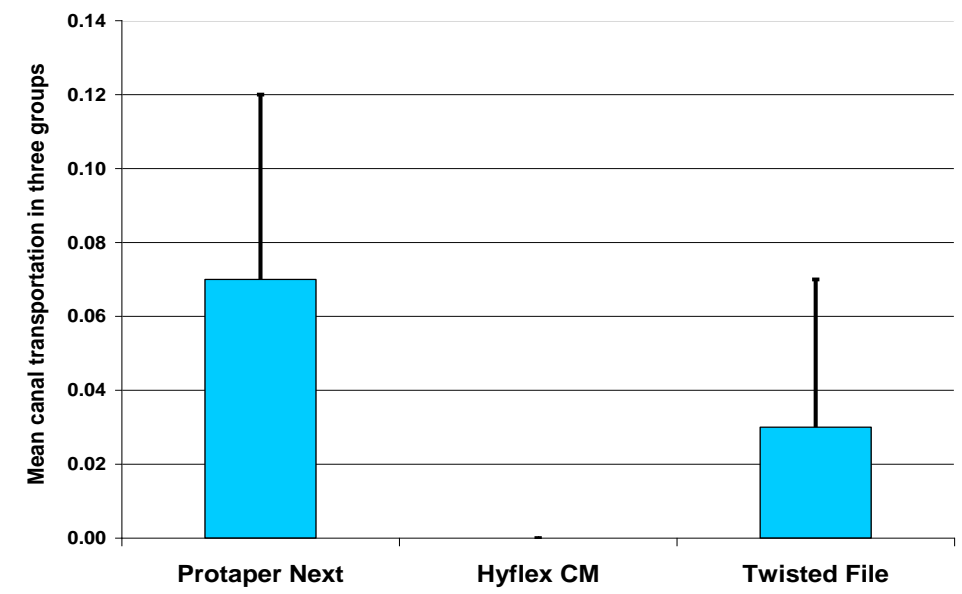

Graph 2: Representation of mean transportation at apical levels in three groups(BL direction)

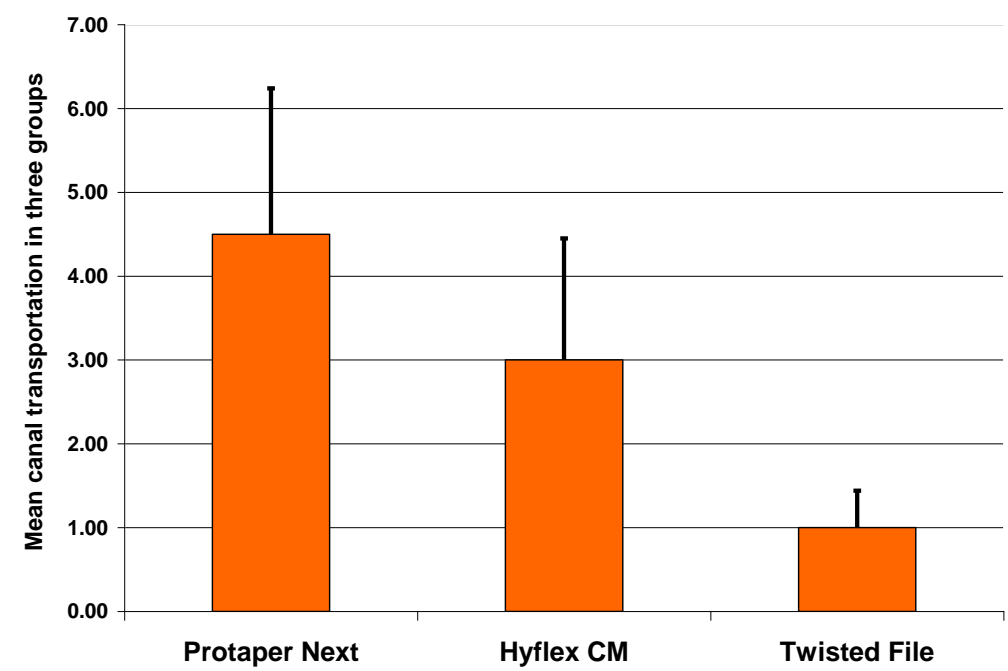

Graph 3: Representation of Centering ability of three groups (MD direction)

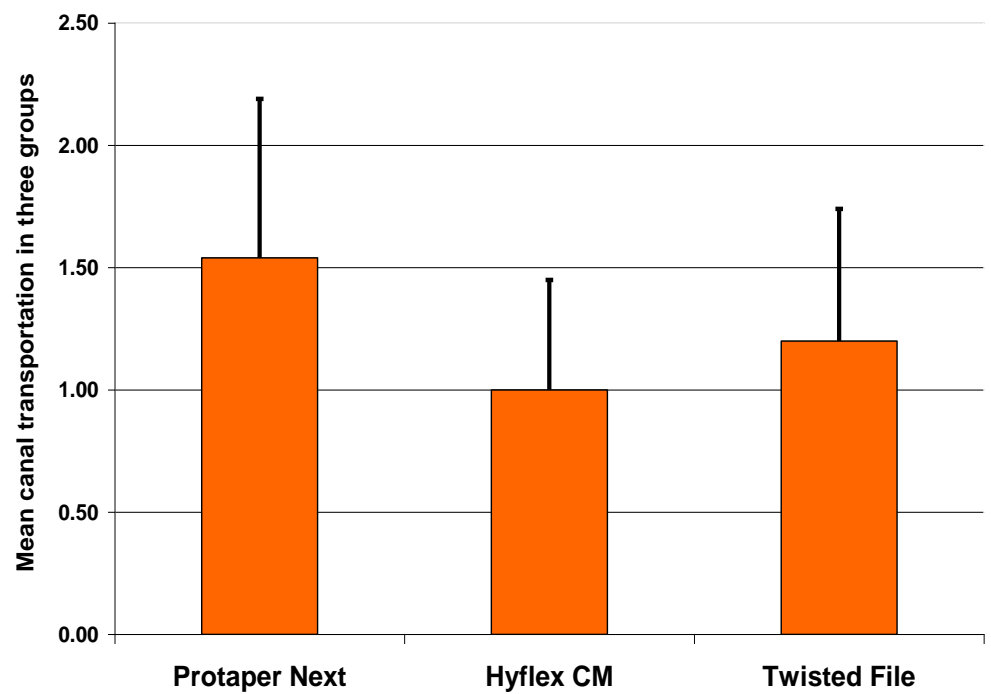

Graph 4: Representation of Centering ability of three groups (BL direction) 


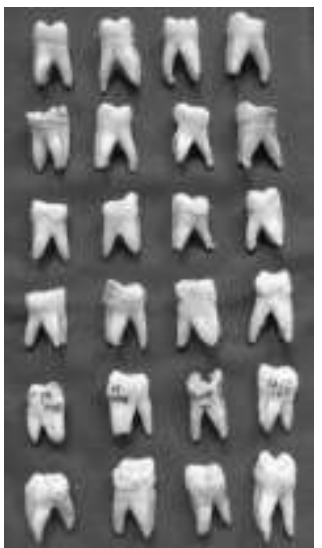

Figure: 1

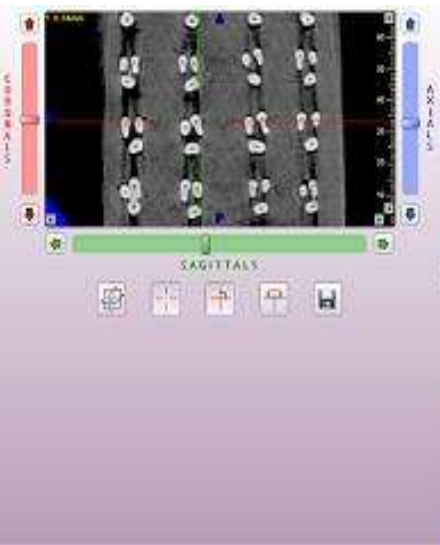

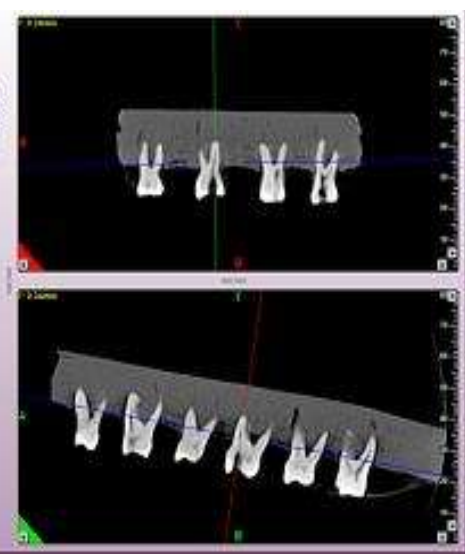

Figure: 2

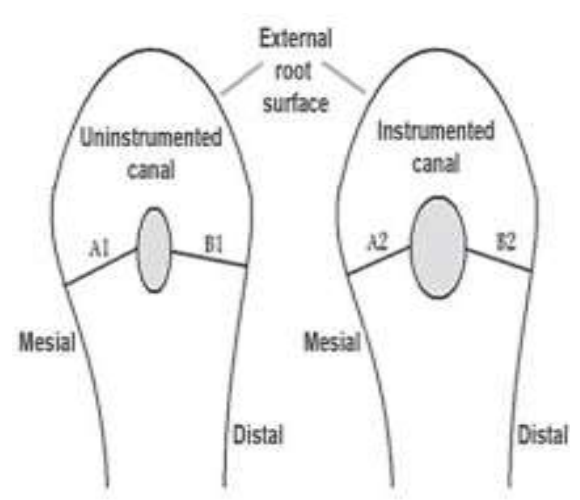

Figure: 3

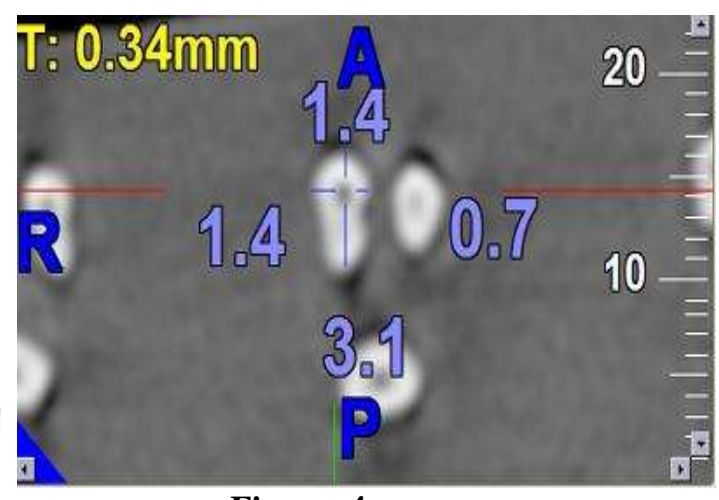

Figure: 4

VI. Tables

Table 1: Mean \pm s.d. of canal transportation in three groups under study

\begin{tabular}{|l|l|l|l|}
\hline Group & $\begin{array}{l}\text { Canal Transportation (Apical) } \\
\text { (Mean } \pm \text { s.d.) }\end{array}$ & F-value & p-value \\
\hline MD & \multirow{2}{|l|}{4.48} & $0.0209^{*}$ \\
\hline A(Protaper Next) & $0.14 \pm 0.04$ & & \\
\hline B (Hyflex CM) & $0.10 \pm 0.03$ & \multirow{2}{*}{3.39} & $0.0486^{*}$ \\
\hline C (Twisted File) & $0.00 \pm 0.00$ & & \\
\hline BL & & \\
\hline A(Protaper Next) & $0.07 \pm 0.05$ & & \\
\hline B (Hyflex CM) & $0.00 \pm 0.00$ & & \\
\hline C (Twisted File) & $0.03 \pm 0.02$ & & \\
\hline
\end{tabular}

* Statistically Significant

Table-2 : Mean \pm s.d. of centering ability of three groups under study

\begin{tabular}{|c|c|c|c|}
\hline Group & $\begin{array}{l}\text { Centering ability(Apical) } \\
\text { (Mean } \pm \text { s.d.) }\end{array}$ & F-value & p-value \\
\hline \multicolumn{4}{|l|}{ MD } \\
\hline A(Protaper Next) & $4.50 \pm 1.74$ & \multirow[t]{3}{*}{3.41} & \multirow[t]{3}{*}{$0.047 *$} \\
\hline B (Hyflex CM) & $3.00 \pm 1.45$ & & \\
\hline C (Twisted File) & $1.00 \pm 0.44$ & & \\
\hline \multicolumn{4}{|l|}{$\mathrm{BL}$} \\
\hline A(Protaper Next) & $1.54 \pm 0.65$ & \multirow[t]{3}{*}{3.38} & \multirow[t]{3}{*}{$0.049 *$} \\
\hline B (Hyflex CM) & $1.00 \pm 0.45$ & & \\
\hline C (Twisted File) & $1.20 \pm 0.54$ & & \\
\hline
\end{tabular}

\section{Conclusion}

Within the experimental conditions the recorded results of canal transportation and centering ability of instruments in curved canals when compared then it was revealed that mesio-distally Twisted files and buccolingually Hyflex CM file exhibited better centering and minimum or nil transportation. Further studies are required for three dimensional observations of preparation quality and to substantiate the result of the present study. 


\section{Acknowledgement}

We are very much thankful to Mr. Symsundar Mandal, Ph. D.(Statistical Officer, Dept. of Epidemiology \& Biostatistics, Chittaranjan National Cancer Institute, 37, S. P. Mukherjee Road, Kolkata -700026, India, Email: ssmandal@ hotmail.com) for his great work as a statistician in this study.

\section{Reference}

[1] Kiumars Nazari Moghadam, Shahriar Shahab, Golriz Rostami,c anal Transportation and Centering Ability of Twisted File and Reciproc: A Cone-Beam Computed Tomography Assessment: Iranian Endodontic Journal 2014;9(3):174-179

[2] Walton RE. Histologic evaluation of different methods of enlarging the pulpcanal space. J Endod 1976;2(10):304-11.

[3] Musani I, Goyal V, Singh A, Bhat C. Evaluation and Comparison of Biological Cleaning Efficacy of Two Endofiles and Irrigants as Judged by Microbial Quantification in Primary Teeth - An In Vivo Study. Int J Pediatr Dent 2009;2(3):15-22.

[4] Anil Dhingra, Ruchi Gupta, Amteshwar Singh; Comparison of Centric Ability of Protaper Next, Wave One \&Protaper using Cone Beam Computed Tomography, ENDODONTOLOGY Volume: 26 Issue 2 December 2014

[5] Parashos P, Messer HH. Rotary NiTi instrument fracture and its consequences.J Endod. 2006;32(11):1031-43

[6] Gambarini G, Grande NM, Plotino G, Somma F, Garala M, De Luca M, Testarelli L. Fatigue resistance of engine-driven rotary nickel-titanium instruments producedby new manufacturing methods. J Endod 2008;34(8):1003-5

[7] Johnson E, Lloyd A, Kuttler S, Namerow K. Comparison between a novelnickel-titanium alloy and 508 nitinol on the cyclic fatigue life of ProFile 25/.04 rotary instruments. J Endod 2008;34(11):1406-9

[8] Kramkowski TR, Bahcall J. An in vitro comparison of torsional stress andcyclic fatigue resistance of ProFile GT and ProFile GT Series X rotarynickel-titanium files. J Endod 2009;35(3):404-7

[9] Gao Y, Shotton V, Wilkinson K, Phillips G, Johnson WB. Effects of raw materialand rotational speed on the cyclic fatigue of ProFile Vortex rotary instruments. J Endod 2010;36(7):1205-9

[10] Shen Y, Qian W, Abtin H, Gao Y, Haapasalo M. Fatigue testing of controlledmemory wire nickel-titanium rotary instruments. J Endod. 2011;37(7):997-1001

[11] Gambarini G, Plotino G, Grande NM, Al-Sudani D, De Luca M, Testarelli L. Mechanical properties of nickel-titanium rotary instruments produced with a new manufacturing technique. IntEndod J 2011;44(4):337-41

[12] Testarelli L, Plotino G, Al-Sudani D, Vincenzi V, Giansiracusa A, Grande NM, Gambarini G. Bending properties of a new nickeltitanium alloy with a lower percent by weight of nickel. J Endod 2011;37(9):1293-5

[13] B Shiva Kumar, SpoortiPattanshetty, Manju Prasad, Sunny Soni, Kirti S Pattanshetty, Shiva Prasad; An in-vitro Evaluation of canal transportation and centering ability of two rotary Nickel Titanium systems (Twisted Files and Hyflex files) with conventional stainless Steel hand K-flexofiles by using Spiral Computed Tomography, Journal of International Oral Health. Sept-Oct 2013; 5(5):107-14

[14] Plotino G, Grande NM, Testarelli L, Gambarini G. Cyclic fatigue of Reciproc and WaveOne reciprocating instruments. IntEndod J. 2012;45(7):614-8

[15] Griffiths IT, Bryant ST, Dummer PM. Canal shapes produced sequentially during instrumentation with Quantec LX rotary nickeltitanium instruments: a study in simulated canals. IntEndod J. 2000;33(4):346-54

[16] Bergmans L, Van Cleynenbreugel J, Beullens M, Wevers M, Van Meerbeek B, Lambrechts P. Progressive versus constant tapered shaft design using NiTi rotary instruments. IntEndod J 2003;36:288-95

[17] Gambill JM, Alder M, del Rio CE. Comparison of nickel-titanium and stainless steel hand-file instrumentation using computed tomography. J Endod 1996;22:369-75

[18] Park H. A comparison of Greater Taper files, Profiles, and stainless steel files to shape curved root canals. Oral Surg Oral Med Oral Pathol Oral RadiolEndod 2001;9:715-8

[19] Matwychuk MJ, Bowles WR, McClanahan SB, Hodges JS, Pesun IJ. Shaping abilities of two different engine-driven rotary Ni-Ti systems or stainless steel balanced-force technique in mandibular molars. J Endod 2007;33:868-71

[20] Endodontics Ingle, Elsevier BC. 5th ed. 2002. p. 775

[21] Gutmann JL. Problem solving in Endodontics.3rd ed. Mosby Inc; 1997. p. 96

[22] Gutmann JL. Problem solving in Endodontics. 3rd ed. Mosby Inc; 1997. p. 105

[23] Deivanayagam Kandaswamy, NagendrababuVenkateshbabu, IlangoPorkodi, GaliPradeep; Canal-centering ability: An endodontic challenge, J Conserv Dent | Jan-Mar 2009 | Vol 12 | Issue 1 